\title{
Evolução da Organização Administrativa Brasileira
}

\author{
Benedicto Silva \\ Fundador da Escola Brasileira de \\ Administração Pública
}

A

$s$ histórias política e administrativa do Brasil não se justapõem, como se fôssem o verso e reverso da mesma medalha. A história administrativa reflete e ecoa a história politica, mas ten:-se desenvolvido por caminhos diferentes, em ritmo de câmaralerta, apresentando ênfases diferentes e tendências diferentes.

Estudada em seus procedimentos e práticas, vista em sua intimidade, porém, a história de nossa administração pública faz revelações interessantes e elucidativas.

Não obstante, a evolução administrativa brasileira jamais atraiu os nossos historiadores. Se bem que meritórias como fontes de subsidios, as obras publicadas sôbre o assunto limitam-se a enumerar pessoas e fatos: os nomes dos donatários de capitania e os dos governadores gerais, na Colônia; os nomes de presidentes e membros do Conselho de Ministros, no Império; os os nomes de presidentes e ministros de Estado, na República; as datas; a longa série de alvarás, atos, leis, decretos e regulamentos; e pouco mais. De modo geral, até agora, não houve tentativa de análise e interpretação.

Talvez essa provincia de nossa história não haja seduzido os estudiosos porque o seu tratamento adequado exija pesquisas extenuantes e análise exaustiva das instituições públicas, desde, pelo menos, 1532, até os dias atuais, através de 4 séculos e meio.

$\mathrm{Na}$ história politica, é possivel a periodização. Podemos dividi-la, desde logo, em três grandes periodos: o período colonial, o período imperial e o periodo republicano. Cada um dêsses, por sua vez, se divide em subperíodos. De qualquer maneira, ai temos as três grandes partes do todo que é a história política do Brasil. 
Já a história administrativa não é suscetível de divisão em períodos definidos. Não se podem indicar datas para fixar, na escala de tempo, as fases de seu desenvolvimento. Qualquer esquema de periodização que se tente aplicar à história administrativa do Brasil esbarra em verdadeiros labirintos cronográficos.

Debruçando-se sôbre ela, entretanto, o observador consegue distinguir algumas fases que são caracterizáveis, embora não se sucedam cronològicamente, como, por exemplo, a República sucedeu ao Império.

Trata-se de fases que se imbricam, se superpõem, correm paralelas, são contemporâneas.

\section{A FASE REINOL}

A primeira que se apresenta é a fase colonial ou reinol, a mais nitida e a mais longa de tôdas. Dominou o período colonial e projetou-se pelo periodo imperial adentro, até, pelo menos, meados do século passado, chegando esmaecida, mas ainda reconhecivel aos nossos dias.

A - fase colonial caracteriza-se pela transplantação sem adaptação: costumes, práticas, procedimentos, rotinas, normas adotadas na metrópole foram transplantados quase in natura e instalados na colônia. Conforme observa Oliveira Viana, "quem quer que se abalance a estudar a evolução do organismo governamental no Brasil, ficará surprêso ao ver, logo nos princípios da nossa nacionalidade, no rudimentarismo das nossas feitorias agrícolas, um aparelhamento político digno de uma sociedade organizada e altamente evoluida". (1)

O exame da nomenclatura dos cargos públicos dá-nos uma idéia das tendências, motivos e interêsses da fase reinol, que tantos males causou ao Brasil. Os funcionários públicos eram patriarcalmente chamados "filhos das fôlhas". Uma lista parcial dos cargos que ocupavam na fase colonial inclui os seguintes: corregedores de comarca, ouvidores, provedores, contadores de comarca, juizes originários, juizes de fora, juizes de vintena, juízes de órfãos, vereadores, almotacés, alcaides, solicitadores dos residuos, procuradores de conselho, tesoureiros, escrivães, tabeliães do judicial, tabeliães de notas, inquiridores, contadores dos feitos, capitães de mato, quadrilheiros, porteiros, recebedores de sisas, meirinhos.

Em seu livro Organização Politica e Administrativa do Brasil, Tavares de Lira acrescenta: "... outros, muitos outros,

(1) Olveira Viana - Populaçóes Meridionais do Brasil. São Paulo, 1938. P. 359. 
alguns dos quais, simples e modestos funcionários administrativos, se enquadravam também entre os serventuários da justiça, porque esta e a administração não estavam separadas por linhas divisórias rigorosas e perfeitas. Confundiam-se, formando o aparelho de compressão e tirania com que a metrópole explorava a colônia, impedindo o surto de suas indústrias, monopolizando o seu comércio e sufocando os seus anseios de progresso e liberdade". (2)

Note-se, desde logo, a multiplicidade de juizes e fiscais, de funcionários incumbidos de julgar e inspecionar. A metrópole estava muito mais empenhada em apurar faltas de que em servir, muito mais preparada para punir do que para favorecer.

Se quiséssemos examinar um documento da fase reinol, para aferir o seu conteúdo social, nenhum mais representativo do que a chamada "exposição de motivos" da Carta Régia com que D. João VI abriu, em 1808, os portos do Brasil. Ela começa assim:

“Attendendo á representação, que fizestes subir á minha Real Presença, sobre se achar interrompido e suspenso o commercio desta Capitania, com grave prejuizo dos meus vassallos e da minha Real Fazenda, em razão das criticas e publicas circunstancias da Europa; e querendo dar sobre este importante objecto alguma providencia prompta e capaz de melhorar o progresso de taes damnos: sou servido ordenar interina e provisoriamente, enquanto não consolido hum systema geral que effetivamente regula semelhantes materias, o seguinte: Primo: Que sejam admissiveis nas Alfandegas do Brasil todos e quaesquer generos, fazendas e mercadorias, transportados em navios estrangeiros das Potencias que se conservam em paz e harmonia com a minha Real Corôa, ou em navios dos meus vassallos, pagando por entrada vinte e quatro por cento; a saber: vinte de direitos grossos, e quatro do donativo já estabelecido, regulando-se a cobrança destes direitos pelas pautas, ou aforamento, por que até o presente se regulão cada uma das ditas Alfandegas, ficando os vinhos, aguas ardentes e azeites doces, que se denominam molhados, pagando o dobro dos direitos, que até agora nellas satisfaziam. Secundo: Que não só os meus vassallos, mas tambem os sobredictos estrangeiros possão exportar para os Portos que bem lhes parecer a beneficio do commercio e agricultura, que tanto desejo promover, todos e quaesquer generos e producções coloniaes, a excepção do Pau Brazil, ou outros notoriamente estancados, pagando por sahida os mesmos direitos já estabelecidos nas res-

(2) A. TAVARES DE LIRA - Organização Politica c Administrativa do Brasil. São Paulo, 1941. P. 40-41. 
pectivas Capitanias, ficando entretanto como em suspenso e sem vigor, todas as leis, cartas regias, ou outras ordens que até aqui prohibiam neste Estado do Brazil e reciproco commercio e navegação entre os meus vassallos e os estrangeiros". (3)

A linguagem autocrática, quase truculenta, dessa Carta Régia, tão festejada pelos historiadores como ato de sabedoria altamente favorável ao progresso do Brasil, documento em que os possessivos meu e minha, meus e minhas se encadeiam como verdadeiros refrões, repetindo e repetindo que tudo pertencia à cabeça coroada, indica o teor absolutista da fase reinol da administração pública no Brasil.

Essa fase não se encerrou com a vinda de D. João VI, quando houve uma espécie de inversão nos papéis entre o Brasil colônia e Portugal metrópole. Transferida a côrte para o Brasil, a colônia passou a ser, por algum tempo, pelo menos, a sede da metrópole, e Portugal ficou reduzido a uma situação de território. Mas a fase colonial não terminou aí, nem terminou em 1822 com a declaração da independência, nem com o advento do II Império. Permeou os costumes, as usanças, os procedimentos da administração até meados do século passado, deixando resíduos que sobrevivem em nossos dias.

Pedro I, em 9 anos de reinado, usou o poder moderador nada menos de doze vêzes para recusar sanção a resoluções legislativas. Pedro II foi um monarca sereno, circunspecto, refletido. No seu longo reinado, dispondo a bel-prazer de poder moderador, que, na verdade, era poder absoluto, jamais fêz uso dêle para vetar qualquer lei.

Mas no estilo com que Pedro II dava contas dos negócios do Estado a seus súditos através das falas do trono, o pesquisador surpreende, ainda bem vivo, o espírito da fase colonial. A fala do trono de 9 de maio de 1868 , por exemplo, começa assim:

"Que tinha o prazer de annunciar que sua filha a princeza d. Leopoldina regressara da Europa com o seu genro o Duque do Saxe e que a 6 de Dezembro do anno passado dera á luz a um principe, que recebeu o nome de Augusto.

"Em todo o Imperio havia tranquillidade publica.

"O Brasil achava-se em paz com as potencias extrangetras.

"Não findara ainda a guerra provocada pelo presidente da republica do Paraguai e depoiś dos sucessos enunciados na fala com que encerrou a sessão legislativa do anno findo, feitos glo-

(3) Manoel Pinto de Aguiar - A Abertura dos Portos - Cairu e os Inglêses. Salvador, 1960. P. 109-110. 
riosos e importantes, quaes os do Potrero Ovelha, o de Taii, a defesa de Tuiuti, a passagem de Humaitá e tomada do Estabelecimento, assim como a repulsa da abordagem dos encouraçados e o ataque e occupação de Curupaiti e de grande parte das linhas inimigas, confirmando cada vez mais o valor de nossas forças de mar e terra e dos alliados, promettiam para breve a honrosa terminação da guerra". (4)

Como se vê, primeiro o monarca fazia referência aos membros da familia imperial, comunicava ao país o nascimento de um neto, o aparecimento de um principe; depois, tratava dos negócios públicos pròpriamente ditos, inclusive da guerra em que o Brasil se achava engajado.

Na fala do trono de 1874 , já se observa ligeira modificação de posição entre os negócios públicos e as pessoas da família real. Informava então o imperador:

“Que, graças á Divina Providencia, a tranquillidade publica conservava-se inabalavel, e o Brasil prosperava sob a influencia deste grande beneficio.

"As ultimas noticias, que tivera de sua filha, princeza imperial condessa d'Eu, trouxeram-lhe a certeza de que se achava de esperanças. Em taes circumstancias devia regressar ao Brasil para satisfazer uma das condições de contracto matrimonial, mas talvez se visse obrigada a evitar tão longa viagem; seguindo o parecer de auctoridades medicas.

"O estado sanitario não fôra satisfactorio em muitos pontos do Imperio; mas, os soffrimentos do povo eram alternados pelos soccorros do Estado e da caridade particular.

"Nossas relações internacionaes não se alteraram e o governo procurava estreital-as cada vez mais pelos vinculos da amizade e dos interesses reciprocos". (5)

O primado da familia imperial sôbre os interêsses gerais exerceu influência muito forte, embora decrescente, na organização administrativa do país, até o advento da República.

O exercicio das funções administrativas, durante a longa fase colonial, era uma espécie de mistério pragmático, monopolizado pelos letrados reinóis, que, sobrevinda a independência, foram a pouco e pouco sendo substituídos pelos letrados brasileiros. Não havia nenhum treinamento especial para o exercício dos cargos públicos. A vontade do principe reinante pairava,

(4) MAx Fleuıss - História Administrativa do Brasit. São Paulo, 1925. P. 304.

(5) MAX Fleuiss - História Administrativa do Brasil. São Paulo, 1925. P. 323. 
soberana, acima de tudo. Êle era o senhor de todos e o proprietário de tudo. O uso freqüente dos possessivos meu e minha nos documentos oficiais não representava uma sobrevivência medieval. Quando falava no "meu erário real", nos "meus vassallos", o Príncipe fazia emprêgo literal e não apenas simbó. lico dos possessivos.

\section{A FASE JURIDICA}

A fase reinol, cujas reumas mais resistentes ainda se encontram na organização administrativa brasileira, cedeu lugar, aos poucos, à fase a que chamamos juridica, igualmente muito bem caracterizada.

A 11 de agôsto de 1827, o govêrno imperial baixou uma lei, um ato, como se chamava então, criando dois cursos de ciências jurídicas e sociais: um em São Paulo, o outro em Olinda.

O Brasil necessitava de novas categorias profissionais, dentre elas figurava em lugar proeminente a de jurista. Já em 1821 o govêrno havia baixado um ato "declarando os bacharéis formados em leis ou em cânones habilitados para os lugares da magistratura, sem dependência da leitura..."

Conquanto não seja possivel determinar a data exata de seu surgimento, a fase juridica delineia-se, começa a despontar na organização administrativa do Brasil aí por volta da sexta década do século XIX. Essa fase caracterizou-se pelo respeito nominal e cego à lei, e igualmente pelo monopólio dos cargos públicos, especialmente dos eletivos, pelos bacharéis em direito.

A famosa frase de Rui Barbosa "com a lei, pela lei e dentro da lei, porque fora da leí não há salvação" (6) pode ser considerada um epítome da fase jurídica.

$\mathrm{O}$ advento da República deu maior vigor à fase jurídica, especialmente no que diz respeito à hegemonia política dos juristas. Os mandatos de presidentes, governadores, senadores, deputados, bem como os cargos de ministros de Estado, embaixadores, secretários de Estado, foram e continuam a ser apanágio dos bacharéis em direito. As estatisticas revelam a êsse respeito, se não monopólio, pelo menos o predomínio indisputado, pacifico e inequivoco dos juristas no exercício e gôzo das funções públicas. Até nos postos administrativos de menor projeção e em certas atividades vitalícias altamente remuneradas, como os cartórios e tabelionatos, o predomínio dos bacharéis em direito é inegável.

Não é difícil, por outro lado, documentar abundantemente certos exageros burocráticos determinados pelo culto cego e au-

(6) Rui Barbosa - Discursos Parlamentares - 1892. Rio de Janeiro, 1947. P. 289. 
tomático da lei. Quem abrir, por exemplo, o Diário Oficial, de 20 de janeiro de 1933 , p. 1400 , encontrará o seguinte edital do Tribunal de Contas:

"Pelo presente edital ficam intimados o $\mathrm{Sr}$. Cícero Osório Venerando de Azevedo, os herdeiros do Sr. José Maria do Monte Thabor e o Sr. Antonio André Gonçalves Teixeira, ex-agentes do Correio em "Carmo da Escaramuça", "Paraguassú" e "Araguari", no Estado de Minas Gerais, para, no prazo de 30 dias, contados da data da publicação dêste, alegarem o que fôr a bem de seus direitos, produzirem documentos ou recolherem, aos cofres públicos, as importâncias de $160 \$ 800,19 \$ 400$ e $26 \$ 400$, alcances verificados nos processos de tomadas de suas contas, referentes aos períodos de 15 de setembro de 1904 a 24 de julho de 1905 , de 1 de agosto de 1896 a 14 de julho de 1903 e de 1 de dezembro de 1894 a 16 de junho de 1895 , respectivamente, sob pena de revelia.

"Terceira Diretoria do Tribunal de Contas, 13 de janeiro de 1933. - Mario Newton de Figueiredo, diretor".

Isso significa que, no ano de 1933,39 anos depois de ocorridos alguns dos fatos a que se refere, o edital publicado no Diário Oficial intima os herdeiros de ex-agentes de correio de remotos povoados de Minas Gerais, a recolherem aos cofres públicos a importância de 19.400 réis, conseqüência de alcance correspondente ao período de $1^{\circ}$ de agôsto de 1896 a 14 de julho de 1903.

A publicação do edital terá custado ao Tesouro Nacional muito mais do que a importância cuja arrecadação improvável poderia determinar. Qual a razão de semelhante ato? Era a observância cega, automática da lei. A lei mandava que assim se fizesse, e, embora com 40 anos de gestação, com 40 anos de atraso, assim se fêz, no momento em que o ato já não tinha sentido.

Não se diga que estamos diante de um caso isolado. Há muitos outros. Possuo documentação sôbre pelo menos vinte casos semelhantes, recolhidos em épocas diferentes. Vejamos o seguinte:

"Pelo presente edital são intimados os herdeiros de ex-agente de Correio em "Urucú de Minas Novas", no Estado de Minas Gerais, Oto Somerlatti, para, no prazo de trinta dias, contados da data da publicação dêste, recolherem, aos cofres públicos, a importância de réis $14 \$ 400$, alcance apurado no processo de tomada de contas do citado ex-agente, referente ao periodo de 1 de janeiro de 1895 a 13 de abril de 1916 , e a cujo pagamento, bem como ao dos juros da mora que forem devidos, foram os 
referidos herdeiros condenados por acórdão de 8 de março de 1921 , sob pena de ser feita a alienação administrativa da fiança do aludido ex-agente".

"Terceira Diretoria do Tribunal de Contas, 14 de outubro de 1933. - Alexandre Emilio Sommier, diretor interino". ( $\mathrm{Pu}$ blicado a páginas 20.867 no D. O. de 1 de novembro de 1933).

Neste caso, os responsáveis pela indenização de $14 \$ 400$ réis ( Cr $\$ 14,40$ na moeda de hoje), correspondente a um alcance apurado no processo de tomada de contas referente ao periodo de $1^{\circ}$ de janeiro de 1895 a 13 de abril de 1916, foram condenados por acórdão de 8 de março de 1921 e intimados a recolher aquela importância pelo Diário Oficial de 1 de novembro de 1933.

Êstes são alguns dos aspectos negativos da fase jurídica. Cumpre-nos apontar também os positivos. Os juristas desempenharam papel impar e formidável na campanha da Abolição, na propaganda republicana e na organização politica e administrativa da República.

Há mesmo quem diga ser a República obra exclusiva dêles. Em um de seus discursos de antologia, Rui Barbosa perguntava afirmativamente - "O próprio Brasil, o Brasil parlamentar, o Brasil abolicionista, o Brasil republicano, que outra coisa não é, senão a obra dos seus homens de Estado, os quais eram, ao mesmo tempo, os seus jurisconsultos e os seus oradores? (7). E em outra ocasião, apostrofava:

"Suprimi (os juristas) ... do Brasil, e tereis acabado com a atividade civilizadora do Império, a luminosa jurisprudência dos seus tribunais, os seus magníficos monumentos de codificaçâo, a educação liberal das classes cultas pela escolha das suas assembléias, a conquista da emancipação pelos comícios populares, a organização da Monarquia e da República, pelas nossas duas Constituições. Tudo, tudo, benefícios do senso jurídico e do senso político, representados e desenvolvidos pela ciência dos nossos legistas e pelo influxo dos nossos parlamentares". (8)

\section{A FASE TAYLORISTA}

A terceira fase, discernivel na evolução da administração pública brasileira, embora muito menos importante, e muito menos evidente, poderia ser cognominada fase taylorista. Seus primeiros sintomas começam a aparecer dois ou três lustres depois da primeira guerra mundial, na terceira década do século atual. A preocupação legalística, até ai dominante no panorama adminis-

(7) Rui Barbosa - Antologia. Rio de Janeiro, 1953. P. 116.

(8) Ibid., P. 117. 
trativo do país, passa a ceder terreno à preocupação do rendimento. As repartições governamentais começam a sentir a atração da eficiência, a preocupar-se com os custos unitários. Aparecem, na literatura oficial, nos relatórios administrativos, nas exposições de motivos, nos projetos de leis, nas mensagens presidenciais, certas palavras e expressões novas, como racionalização, organização cientifica do trabalho, estudos de tempo e movimentos, seleção de pessoal, organogramas, fluxogramas, etc.

Datam dessa fase várias iniciativas e resoluções do govêrno federal, algumas legislativas, outras executivas, evidentemente inspiradas pelas idéias tayloristas.

Não pretendendo apresentar, desta feita, lista exaustiva de tais providências, limitamo-nos a apontar as seguintes:

a) A inclusão, pela reforma Rocha $V_{A z}$, no currículo das Escolas de Engenharia, de uma cadeira ministrada no $3^{\circ}$ ano para todos os cursos de engenharia e denominada: "Organização e tráfico das indústrias, Contabilidade Pública e Industrial e Direito Administrativo". A reforma Francisco Campos, de abril de 1931, manteve essa cadeira, modificando-lhe, porém, o titulo para "Organização das Indústrias, Contabilidade Pública e Industrial, Direito Administrativo, Legislação (de Águas, Minas, Terras e. Trabalho)".

b) A criação, em 1931, do Departamento Federal de Compras no Ministério da Fazenda, destinado a centralizar a aquisição de material permanente e de consumo para o serviço público civil.

c) A padronização dos artigos de papel para expediente.

d) A padronização dos móveis e equipamentos das repartições públicas. União.

e) A padronização dos vencimentos dos servidores civis da

f) A criação das Comissões de Eficiência nos Ministérios.

g) $\mathrm{O}$ estabelecimento de normas financeiras para os Estados e municípios.

h) a revisão dos topônimos do Brasil.

A propósito de algumas dessas medidas cabem comentários adicionais, para situá-las no esquema geral do esfôrço de taylorização, mais ou menos desordenado, que entre os anos de 1925 e 1945 se fêz no Brasil.

A padronização dos artigos de papel de expediente, por exemplo, representou progresso indiscutivel. Basta mencionar que na Presidência da República e nos 6 ministérios civis então existentes, havia em uso nada menos de 481 tipos diferentes de envelopes oficiais, variando na côr, no formato, nos tipos das 
letras, no tamanho do emblema, na timbragem. Essa mesma anarquia campeava nos demais artigos do expediente: papel de ofício, papel de carta, cartões, etc. A Comissão Permanente de Padronização fêz obra meritória. Para citar apenas um de seus feitos - reduziu os 481 tipos de envelopes a quatro apenas. $\mathrm{O}$ que isso representa, em têrmos de economia, seria difícil de avaliar, mas certamente representa soma considerável.

A padronização da nomenclatura e vencimentos dos funcionários civis da União, realizada em 1936, também constitui passo gigantesco para a racionalização administrativa do Brasil. Resultado de vários séculos de administração empirica, havia então mais de 500 tipos de vencimentos no serviço público federal, variedade que, longe de espelhar diferenças de capacidade e de responsabilidade funcionais, apenas refletia uma acumulação de desordem.

Além da existência de muitos servidores desempenhando as mesmas funções, mas sob designações diferentes, havia muitos com designação idêntica, mas desempenhando funções diversas. Havia, por exemplo, desenhistas, desenhistas de $1^{\text {a }}$ classe, desenhistas de $2^{a}$ classe e desenhistas-chefes, todos ganhando o mesmo salário. Havia oito níveis diferentes de remuneração para os primeiros escriturários. Inclusive no caso de funções simples, com a de carroceiro, as modalidades de pagamento e os quantitativos variavam de repartição para repartição, muitas vêzes dentro do mesmo Ministério.

A desordem de nomenclatura, vencimentos e classificações era tamanha que dois ocupantes de cargos de funções técnicas absolutamente iguais eram chamados, um, fotomicrógrafo, no Instituto de Biologia Vegetal, do Ministério da Agricultura, e outro, microfotógrafo, no Instituto Osvaldo Cruz, do Ministério da Educação. Além disso, o fotomicrógrafo percebia 14:400\$000 por ano, e o microfotógrafo apenas 12:000\$000 por ano.

Havia, espalhados pelos nove ministérios, 300 carpinteiros, aos quais correspondiam 48 modalidades distintas de vencimentos. A lei 284 , de 28 de outubro de 1936 realizou uma extraordinária operação de simplificação, policiando os títulos dos cargos, criando cêrca de 100 carreiras profissionais para ordenar o caos existente, e reduzindo a escala de vencimentos a apenas 27 padrões.

Animados com os brilhantes êxitos obtidos até então nas aplicações das idéias de Taylor, não tardamos em descambar para algumas leviandades. Em nossa aceitação incrítica dos princípios tayloristas, chegamos a deformá-los e até corrompê-los, por exagêro. Houve um momento em que a ordem era simplificar, padronizar e uniformizar. Nessa febre de taylorização exaltada, fomos longe demais. Fomos, por exemplo, ao extremo iconoclás- 
tico de decretar a revisão geral dos topônimos brasileiros e proibir, por decreto-lei, a identidade de nomes a cidades e povoados. Alegou-se que a existência de duas ou mais cidades com o mesmo nome, embora uma na Bahia, outra em Minas e a terceira em Goiás, perturbava o ensino de geografia politica e facilitava o extravio de correspondência.

O poder central impôs, então, aos municípios de todo o pais, mudanças revoltantes e absurdas de nomes, violentando inùtilmente os sentimentos e tradições locais.

Denominações seculares repentinamente ruíram por terra, sendo substituidas por nomes artificiais, inexpressivos, inventados pela fantasia tola de seus proponentes.

Graças a essa taylorização exuberante e adulterada, cidades tradicionais, como Santa Cruz, Santa Luzia e Bonfim, no Estado de Goiás, com mais de 100 e até 200 anos de existência sob essas denominações históricas, tiveram de repente os nomes mudados por decreto, à revelia e ao arrepio de sentimento local. Santa Luzia, um dos topônimos mais belos da lingua portuguêsa, Santa Luzia, que soa à maneira de música em ouvidos educados, que em sonoridade e beleza se equipara a Caravelas, Valparaíso e Los Angeles, passou a chamar-se Luziânia. A vetusta Santa Cruz passou a chamar-se Potira; Bonfim, Silvânia. Ainda no Estado de Goiás, Santa Rita do Paranaiba foi rebaixada a Itumbiara e Tôrres do Rio Bonito, a Caiapônia - outras tantas atrocidades campanudas; Bela Vista recebeu o nome de Susstapara; Campo Formoso, meu torrão natal, o apelidinho ridículo de Orizona.

A influência de Taylor na administração pública brasileira foi benéfica, sem dúvida, nas aplicações judiciosas, mas certamente exagerada e até grotesca, nas aplicações superficiais.

A fase taylorista não chegou, porém, a imprimir seu signo na administração do Brasil tão profundamente quanto as fases anteriores.

\section{A FASE DAS RELAÇÕES HUMANAS}

Antes de consolidar-se, a fase taylorista já está sendo abalada pela fase mais recente, que ainda se encontra no limiar de seu advento, a fase atual, a que podemos chamar, indistintamente, fase das relações humanas, fase antropológica, ou fase psicológica. Esta ainda não se infiltrou nas instituições públicas do país; está apenas acampada em barracas provisórias em alguns setores mais esclarecidos. Orienta-se pelo esfôrço de dignificar a pessoa humana e compreender, não pela via legal, não pela via mecanicista, tampouco pela interpretação materialista, mas pela via mais complexa dos motivos humanos, as causas miste- 
riosas que fazem o trabalhador gostar do trabalho ou aborrecê-lo, sentir-se bem ou mal ajustado na emprêsa.

Essa fase tende a caracterizar-se pelo empenho deliberado de pesquisar a fundo os móveis humanos. Que é que faz o trabalhador gostar do trabalho? Que é que o leva a sentir se ajustado na emprêsa, na repartição, ou, ao contrário, detestar o trabalho, sentir-se infeliz no emprêgo? Serão boas condições higiênicas, confôrto físico, serão salários elevados ou será um con junto eclético de causas?

Esta é a fase que está apenas aportando a nossa cultura, fase da qual é pioneira a Escola Brasileira de Administração Pública, da Fundação Getúlio Vargas. Não só a Escola criou seus cursos de relações humanas, senão também está tentando forjar o profissional que deverá ser para essa nova fase o que o jurista tem sido para a fase jurídica. Cumpre preparar o homem adequado para desempenhar as funções correspondentes.

\section{A INTERPRETAÇÃO DAS FASES}

Um corte transversal, no sentido físico, da administração pública brasileira, poria em relêvo traços remanescentes da fase colonial, o rico filão da fase jurídica, os vestígios recentes da fase taylorista, que não chegou ao estágio de floração, e os sintomas incipientes da fase antropológica.

Exceto no caso da fase colonial ou reinol, que por sua duração e natureza empolgou inteiramente as instituições públicas do país, a administração brasileira jamais chegou a ser dominada por qualquer das outras fases. Em muitos casos, apenas partes da administração, setores restritos e mesmo individuos isolados é que foram objeto de mudança. Nem mesmo a fase reinol, a mais remota de tôdas, foi completamente suplantada. Ainda há reumas coloniais em redutos tradicionalistas de nossa administração pública. Já não falamos em almotacés, homens bons, capitãesmores, provedores, ouvidores, juizes de fora, mas usamos expressões como direitos de importação, sisa, amanuense, meirinho, escrivão de órfãos, e outras que representam sobrevivências tranquuilas das instituições coloniais.

$\mathrm{Na}$ fase colonial, a administração pública é uma espécie de mistério pragmático, capaz de ser aprendido a poder de rotina e praticado a ôlho.

$\mathrm{Na}$ fase jurídica, um ritual especializado e privativo, rìgidamente regulado pela lei. $\mathrm{Na}$ fase taylorista, a administração tende a ser uma técnica científica, muito mais preocupada com o rendimento do trabalho e o modus operandi do trabalhador do que com a observância religiosa da lei. $\mathrm{Na}$ fase antropológica 
- é de prever-se -, a administração transfigura-se em atividade profissional complexa, cujo exercício requer equipamento intelectual igualmente complexo a que sejam incorporados elementos das outras fases, bem como conhecimentos e métodos de trabalho originários de outras categorias profissionais.

Apesar de paralelas e por vêzes mescladas, não é difícil identificar o teor profissional dominante das três primeiras fases: o artífice da fase colonial era o letrado reinol; o da fase juridica, n legista, o exegeta da lei, numa palavra, o bacharel em direito; o da fase taylorista, o engenheiro industrial.

\section{EFEITOS CUMULATIVOS DAS QUATRO FASES}

Parece, pois, demonstrável que o desenvolvimento da organização administrativa do Brasil se vem processando ao longo e através de várias fases, que, embora reflitam a história política, não coincidem com ela na periodização.

A primeira, a mais longa, a mais veemente, a que deixou vestígios mais profundos, a fase reinol ou colonial, que abarca desde o descobrimento até os dias contemporâneos, começou a perder vigor gradativamente a partir da sexta década do século passado.

Em seguida, tivemos a fase jurídica, que começou não em 11 de agôsto de 1827, com a criação dos cursos juridicos, mas uma geração depois, 30 ou 40 anos depois, o que se caracteriza pelo culto da lei, pelo formalismo impenitente, pela volúpia de cumprir a lei, pelo ideal inatingivel de dar à sociedade não um govêrno de homens, mas um govêrno de leis.

A terceira, a que chamamos fase taylorista, não chegou a instalar-se longamente e completamente nas instituições administrativas do Brasil como as fases que a precederam. Resultou de nossa sensibilidade ao progresso geral, de nossa capacidade de captar e utilizar, em benefício da solução de nossos problemas, idéias e modos de ver procedentes de outros países. Da quarta fase, pouco se pode falar por enquanto: está apenas emergindo, batendo às portas de nosso mecanismo administrativo.

Os efeitos cumulativos dessas fases, especialmente da primeira e da segunda, podem ser percebidos no organograma da administração federal do Brasil.

Como não podia deixar de ser num país da extensão, da potencialidade e da vitalidade do Brasil, a estrutura administrativa federal é complexa, labirintica, formada, como foi, a pouco e pouco, pela criação de órgãos novos, consultivos, autárquicos e cutros, à medida que o Estado Brasileiro, mais e mais premido pelos grupos de pressão e orientado pela moderna filosofia politi 
ca, passou a incluir em sua agenda de trabalho novas responsabilidades sociais.

Conquanto não traduza a fisiologia dessa máquina imensa e. complicada, o organograma da estrutura administrativa federal mostra convencionalmente um corte transversal de sua anatomia. Revela a hipertrofia da Presidência da República e o definhamento progressivo da administração tradicional representada pelos Ministérios, dois sintomas de patologia administrativa.

Com efeito, muitos dos órgãos mais operantes da administração federal, aquêles que têm a seu cargo o estudo, o encaminhamento e a solução dos problemas mais prementes com que o país se vê a braços - como o do desenvolvimento econômico, e da queimação de etapas no processo da industrialização trabalham à revelia dos Ministẹ́rios, ou, por circunstâncias politicas, estão localizados em Ministérios que foram criados e são mantidos para outros fins.

O impulso de industrialização emanou da Presidência da República e produz seus efeitos não através do Ministério competente para fazê-lo, então o Ministério do Trabalho, Indústria e Comércio, mas através de órgãos extraministeriais, como o Conselho do Desenvolvimento, o Banco Nacional do Desenvolvimento Econômico e os grupos de trabalho como GEIA e o GEICON, os quais, embora ligados ao Ministério da Viação e Obras Públicas, não se integram na órbita de ação daquele Ministério.

Os efeitos cumulativos do impacto das fases que marcam o desenvolvimento da organização administrativa do Brasil assumem proporções mais evidentes no congestionamento da Presidência da República, que deixou de ser o núcleo nobre e supremo da Chefia Executiva, para se transformar no ancoradouro, no refúgio de tôda espécie de órgãos administrativos, consultivos, mistos, permanentes alguns, temporários outros, que têm proliferado nestes últimos vinte anos.

\section{A PRESIDÊNCIA DA REPÚBLICA}

Tal como existia no dia 25 de agôsto de 1961 (9) a Presidência da República do Brasil compreendia, subordinava ou

(9) Pareceu-nos prudente escolher a data de 25 de agôsto de 1961 como ponto de referêricia para mostrar os efeitos acumulados $d_{a}$ deso-dem administrativa na Presidência da República. Pràticamente a partir dessa data (e em conseqüência da crise que o seguiu) o Brasil adotou um sistema parlamentar de tonalidade cabocla, que ainda está ensaiando os 
tutelava 100 órgãos e entidades diversas, de 11 categorias diferentes, conforme em seguida se enumera:

$$
\text { A - ÓRgãos MINISTERIAIS }
$$

\section{I - Ministérios}

1. Ministério da Aeronáutica

2. Ministério da Agricultura

3. Ministério da Educação e Cultura

4. Ministério da Fazenda

5. Ministério da Guerra

6. Ministério da Indústria e Comércio

7. Ministério da Justiça e Negócios Interiores

8. Ministério da Marinha

9. Ministério das Minas e Energia

10. Ministério das Relações Exteriores

11. Ministério da Saúde

12. Ministério do Trabalho e Previdência Social

13. Ministério da Viação e Obras Públicas

$$
\text { B - ÓRGÃOS NÃO-MINISTERIAIS }
$$

II - Ótgão de Planejamento Politico-Militar, estabelecido pela Constituição

\section{Conselho de Segurança Nacional}

III - Autarquias

1. Instituto Brasileiro de Geografia e Estatística

2. Conselho Nacional de Pesquisas

3. Conselhos Federal e Regionais de Medicina

primeiros passos, procurando ajustar-se às peculiaridades e exigências nacionais.

No momento não existe aquilo a que se poderia chamar chefia executiva una: existe uma chefia executiva dicotomizada entre a Presidência da República e a Presidência do Conselho de Ministros. Mas, os efeitos da caótica evolução da organização administrativa brasileira continuam a fazer sentir-se, sem dúvida, na Chefia Executiva Brasileira, esteja ela em duas ou em quat:o mãos.

Nossa pesquisa não abrange, entretanto, nenhum momento do regime parlamentarista instituido rsa. Brasil em setembro de 1961. Por essa razão. preferimos argumentar em tôrno da Presidência da República tal como existia nos últimos dias do regime presidencialista.

E' bem possivel que certas considerações constantes da presente pesquisa sejam suscetiveis de modificações em consequiência do nôvo regime. $O$ que desejamos deixar claro é çue esta pesquisa cobre a organização da administração pública brasileira da Colônia à República, mas sòmente até o inomento em que passamos do regime presidencialista, adotado em 1891, para o regime parlamentarista, adotado em 1961. 
IV - Órgãos Independentes, de Administração Direta, criados por lei

1. Comissão Coordenadora da Criação do Cavalo Nacional

2. Comissão de Readaptação dos incapazes das Fôrças Armadas

3. Comissão do Vale do São Francisco

4. Comissão Permanente do Livro do Mérito

5. Comissão de Tarifas

6. Conselho da Ordem Nacional do Mérito

7. Departamento Administrativo do Serviço Público

8. Estado-Maior das Fôrças Armadas

9. Superintendência do Desenvolvimento do Nordeste

10. Superintendência do Plano de Valorização Econômica da Amazônia

11. Superintendência do Plano da Valorização Econômica da Região da Fronteira Sudoeste do País

$\mathrm{V}$ - Órgãos independentes, de Administração Direta, criados por decreto

1. Assessoria do Planejamento Econômico

2. Assessoria Técnica

3. Comissão Brasileira de Operação Pan-Americana

4. Comissão Brasileira de Turismo

5. Comissão de Amparo à Produção Agropecuária

6. Comissão de Desenvolvimento da Pesca

7. Comissão de Estudos e Projetos Administrativos

8. Comissão de Telecomunicações

9. Comissão do Desenvolvimento Centro-Oeste

10. Comissão Especial de Faixa de Fronteira

11. Comissão Executiva de Armazéns e Silos

12. Comissão Nacional de Planejamento de Habitação Popular

13. Comissão Coordenadora do Abastecimento Nacional

14. Conselho de Desenvolvimento

15. Gabinete Civil da Presidência da República

16. Gabinete Militar da Presidência da República

17. Grupo Executivo da Indústria Automobilistica

18. Grupo Executivo de Armazéns e Silos

19. Grupo Executivo da Indústria de Máquinas Agrícolas e Rodoviárias

20. Grupo Executivo da Indústria de Material Aeronáutico

21. Grupo Executivo da Indústria do Cinema

22. Grupo Executivo da Indústria Mecânica Pesada 
23. Grupo Executivo da Indústria Metalúrgica

24. Grupo Executivo da Indústria Naval

25. Grupo de Trabalho de Brasilia

26. Instituto Brasileiro de Estudos Afro-Asiáticos

27. Serviço Nacional dos Municípios

VI - Órgãos de Administração Tertitorial

1. Administração do Território do Acre

2. Administração do Território do Amapá

3. Administração do Território de Rondônia

4. Administração do Território do Rio Branco

$$
\text { C - D́Rgãos SEMIMINISTERIAIS }
$$

VII - Trata-se de três órgãos colegiais que, apesar de funcionarem sob a presidência de Ministros de Estado, não pertencem formalmente a qualquer Ministério e, por conseguinte, gravitam na órbita da Presidência da República.

São êles:

Criado por lei:

1. Comissão de Reparações de Guerra, sob a presidência do Ministro das Relações Exteriores

Criados por decretos:

2. Comissão da Campanha Nacional de Aperfeiçoamento do Pessoal de Nivel Superior, sob a presidência do Ministro da Educação e Cultura

3. Conselho Nacional de Administração de Empréstimos Rurais, sob a presidência do Ministro da Fazenda.

\section{ENTIDADES DIVERSAS}

Existem, ainda, trinta e oito entidades diversas, que de uma ou outra maneira, mais em alguns casos, menos em outros, igualmente concorriam para o congestionamento da Presidência da República, em virtude dos contatos que com ela mantinham:

I - Sociedades de Economia Mista

1. Banco do Brasil S. A.

2. Banco de Crédito da Amazônia

3. Banco do Nordeste do Brasil

4. Centrais Elétricas do Médio São Francisco 
5. Companhia de Eletricidade de Manaus

6. Companhia de Eletricidade do Alto São Francisco

7. Companhia de Navegação do São Francisco

8. Companhia Hidrelétrica de Campo Grande

9. Companhia Nacional de Seguros Agrícolas

10. Companhia Urbanizadora da Nova Capital do Brasil

11. Rêde Ferroviária Federal S. A.

12. Sociedade Termelétrica de Capivari

13. Usina Termelétrica de Figueira S. A.

II - Fundações Instituidas pela União

1. Fundação Abrigo do Cristo Redentor

2. Fundação Brasil Central

3. Fundação da Casa Popular

4. Fundação das Pioneiras Sociais

5. Fundação de Assistência aos Garimpeiros

6. Fundação Getúlio Vargas

7. Fundação Osório

8. Fundação Rádio Mauá

9. Fundação Serviço Especial de Saúde

III - Entidades Mistas de Cooperação Internacional

1. Comissão Brasileiro-Americana de Educação Industrial

2. Comissão Brasil-França do Desenvolvimento Econômico

3. Comissão Mista Brasil-Alemanha de Desenvolvi mento Econômico

4. Comissão Mista Ferroviária Brasil-Bolivia

5. Comissão Mista Brasil-Bolivia de Estudo e Aproveitamento do Petróleo

6. Comissão Mista Brasil-Holanda de Desenvolvimento Econômico

7. Comissão Mista Militar Brasil-Estados Unidos da América do Norte

8. Cooperação Técnica Brasileiro-Americana (Ponto IV)

IV - Entidades Colaboradoras da Administração Federal

1. Associação dos Servidores Civis do Brasil

2. Fundação Darcy Vargas

3. Legião Brasileira de Assistência

4. Ordem dos Advogados

5. Serviço Nacional de Aprendizagem Comercial. 
6. Serviço Nacional de Aprendizagem Industrial

7. Serviço Social da Indústria

8. Serviço Social do Comércio

Excluidos os treze Ministérios, divisões primárias, clássicas, de qualquer govêrno nacional, e as trinta e oito entidades diversas, restam nada menos de quarenta e nove órgãos vários - quase todos avulsos, desintegrados, flutuantes - diretamente vinculados à Presidência da República.

Dêsse total de quarenta e nove, apenas quatro são, de fato, integrantes da Presidência da República:

1. Gabinete Civil

2. Gabinete Militar

3. Estado-Maior das Fôrças Armadas

4. Departamento Administrativo do Serviço Público

E há um, que é complementar:

1. Conselho de Segurança Nacional.

\section{CONCLUSÕES}

O presente ensaio de estudo da organização administrativa do Brasil à luz de seu desenvolvimento histórico e sociológico afiança as seguintes conclusões, entre outras:

1.) A organização administrativa do Brasil apresenta caracteristicas de colcha de retalhos: é eclética, difusa, anárquica, macrocéfala e propícia à centralização patológica.

2a) A evolução daquilo a que podemos chamar a organização administrativa do Brasil processa-se lentamente através de fases marcadas, primeiro pela influência reinol portuguêsa, depois pelas sucessivas correntes de idéias que se têm incorporado à cultura do país.

3a) As tentativas de introdução da administração científica no organismo governamental do país afetaram apenas a periferia, deixando intacto o centro principal, a Presidência da República, que hoje oferece o aspecto de cacho descomunal de órgãos, hipertrofiado por dezenas de unidades que deveriam estar localizadas em outros niveis da hierarquia, notadamente nos ministérios.

4:) A estrutura administrativa do Brasil, certamente obsoleta e primitiva, está longe de corresponder às necessidades atuais do govêrno e ao acréscimo incessante de suas responsabilidades. 
5:) Urge levar a efeito uma reforma administrativa exemplar, concebida e contrastada à luz dos últimos desenvolvimentos da ciência e arte da administração.

6:) O Brasil marcha trabalhosa mas resolutamente para ser um dos países decisivos do Ocidente. Cumpre-nos dar-lhe os instrumentos de progresso e aperfeiçoamento de que necessita para evitar erros e desperdicios em sua marcha ascensional. 